\section{KJÆRE LESER}

Vi er stolte av å kunne gi deg en utvidet spesialutgave av Babylon som både er dedisert til og bygger tematisk på det akademiske virket til statsviter og professor Nils A. Butenschøn. Dette festskriftet kommer i forbindelse med Butenschøns 70-årsdag 21. januar 2019. Her er ikke poenget primært å kaste glans over en jubilant. Anledningen handler snarere om å hylle Butenschøns nasjonale og internasjonale bidrag til Midtøstenforskningen gjennom en imponerende karriere.

Få har gjort så mye for å kaste lys over Midøsten som region og områdefag i Norge som Nils A. Butenschøn. Hans mangfoldige akademiske virke spenner fra Nansenskolen, Norsk Utenrikspolitisk Institutt (NUPI), Institutt for statsvitenskap ved Universitetet i Oslo (UiO) (1990-1998), og Norsk senter for menneskerettigheter, Juridisk fakultet ved $\mathrm{UiO}$, sistnevnte som direktør (1998-2004 og 2009-2013). I disse årene har Butenschøn utmerket seg gjennom sitt omfattende arbeid med publikasjoner om temaer innen statsborgerskap, nasjonsbygging, statsutvikling, politisk representasjon i konfliktområder, demokratiteori i etnisk sammensatte samfunn og menneskerettigheter.
Internasjonalt anses Nils A. Butenschøn å være grunnlegger av statsborgerskapstilnærmingen (citizenship approach) i studiet av politiske forhold i Midtøsten. Statsborgerskapstilnærmingen belyser noen grunnlagsproblemer, slik som: Hva binder borgere og ikke-borgere sammen i ulike former for politiske fellesskap? Hvilke dilemmaer oppstår når statsborgerskap blir et sentralt organiserende prinsipp i post-koloniale stater i Midtøsten? Hvordan studere spenninger mellom samfunnsgrupper og styrende eliter i forsøk på å skape legitimitet og politisk orden? Kjernen i statsborgerskapstilnærmingen ligger, slik Butenschøn skisserer det analytisk, i to måter å forstå maktutøvelse i en stat på: For det første, som en nedenfra-opp-prosess der innbyggere gjør krav på rettigheter gjennom politisk mobilisering, opprør eller borgerkrig. Slik utøves medborgerskap i utformingen og endring av ulike former for politiske fellesskap, også blant innbyggere som ikke har fulle borgerrettigheter som for eksempel kvinnelige borgere, flyktninger og statsløse. For det andre, som en ovenfra-ned-prosess der herskere styrer ved å fordele rettigheter og plikter i en stat. Her er autoritære så vel som demokratiserende former for maktbruk sentrale i belysingen av ekskluderende og inkluderende former for styring. 
Statsborgerskapstilnærmingen skisseres teoretisk, tematisk og ved bruk av stater som eksempler i boken Citizenship and the State in the Middle East: Approaches and Applications som Butenschøn redigerte sammen med Uri Davis og Manuell Hassassian. Tvillingboken Gender and Citizenship in the Middle East, redigert av Suad Joseph, utkom på Syracuse University Press i 2000. Begge er standardverk innen forskning på statsborgerskap i Midtøsten, og var et resultat av en konferanse initiert og arrangert ved Universitetet i Oslo i 1996 under ledelse av Butenschøn. For sin innovative forskningsbaserte undervisning for hovedfagsstudenter i statsvitenskap tilknyttet prosjektene «The Gulf Crisis 1990-1991 and the Restructuring of the Middle East» og "Citizenship in the Middle East» mellom 1991-1997 fikk Nils A. Butenschøn UiOs Læringsmiljøpris i 1997.

Statsborgerskapstilnærmingen fikk fornyet aktualitet etter De arabiske opprør i 2011. I samarbeid med historiker Roel Meijer ved Radboud Universitetet i Nederland har Butenschøn redigert to nye verk som bygger på og utvider statsborgerskapstilnærmingen som teoretisk og analytisk perspektiv i studiet av politisk endring i Midtøsten: The Crisis of Citizenship in the Arab World (E. J. Brill, 2017) og The Middle East in Transition: The Centrality of Citizenship (Edward Elgar Publishing, 2018). I begge bøkene danner statsborgerskapstilnærmingen utgangspunkt for å forstå dynamikken i nedenfra-opp-former for sosial mobilisering blant demonstranter som krevde endringer i styresettet, og ovenfra-ned-utøvelse av makt gjennom regelrett voldsbruk overfor opprørere og politiske motstandere, eller ved endring av lover, konstitusjoner og administrative regimer på måter som befestet makthaveres posisjon ytterligere.
Til dette spesialnummeret av Babylon har vi invitert ledende forskere til å bidra med vitenskapelige artikler som ligger tematisk nært Butenschøns arbeid. Vi har for anledningen også invitert internasjonale størrelser utenfor Nordens grenser som Butenschøn har jobbet tett med. Resultatet er 13 originale og brennaktuelle artikler som på ulikt vis tar pulsen på samtidens Midtøsten og som dveler ved noen av de mest sentrale problemstillingene regionen står overfor.

Innledningsvis reflekterer nestorene INGA BRANDELL Og ANNIKA RABO over midtøstenforskningens historie i Sverige og Norden med utgangspunkt i framstillinger av Orienten, og de skisserer perspektiver for framtidige forskningsfelt. Bidragene i spesialnummeret av Babylon er deretter delt inn i tre bolker: stat, statsborgerskap og territorium. Disse tre nøkkelordene avspeiler ulike aspekter ved Butenschøns forskningsfelt.

Nøkkelordet «stat» antyder at den territoriale statens forutsetninger og etterdønninger i Midtøsten fortsatt er komplekse, og at maktutøvelse skjer gjennom formelle institusjoner som domstoler og parlamentariske valg, så vel som uformelt gjennom herskende eliters kooptering av etniske og religiøse grupper. JOAKIM PARSLOW drøfter hvordan Det osmanske rikets sentrum, dagens Tyrkia, viser imperiale krefter ved underminering av domstolenes makt. Han ser på etterdønningene av kuppforsøket i juli 2016 under president Recep Erdoğan og hans Rettferds- og utviklingsparti (AKP) da mer enn 4000 dommere - en fjerdedel av Tyrkias 12 ooo dommere og påtalejurister - fikk sparken. Parslow drøfter hvorvidt tyrkiske domstoler gjennomgår en «de-konstitusjonalisering» av deres rolle etter at regjeringen har overtatt funksjoner som normalt tilhører parlamentet, og eksplisitt forbudt domstolene å blande seg inn. 
MORTEN VALBJøRN Og RAY HINNEBUSCH ser på konfliktdynamikken i delte samfunn i blant annet Syria, Kuwait og Bahrain, og drøfter politiseringen av den regionale konfliktlinjen mellom sjiaer og sunnier. De ser på styresmakters bruk av sekterisme som politisk virkemiddel for å opprettholde sin makt etter 2011. Forfatterne har som mål å belyse hvordan ulike autoritære regimer har beholdt makten sin på gjennom voldelige opprør, og med det bidra analytisk til debatten omkring oppgradering av autoritarianisme (upgrading of authoritarianism) i studiet av autokratiske regimer i Midtøsten.

KJETIL SELVIK tar utgangspunkt i parlamentsvalget i Irak i mai 2018, og viser hvordan religiøs autoritet i forkant av valget veiet opp for legitimitetsunderskuddet til verdslige styresmakter i landet. Han trekker fram måten religiøse ledere som 88-årige ayatollah Sistani og hans tilhengere veksler religiøs symbolsk kapital i politisk valuta i form av stemmer og politiske posisjoner i parlamentet. Selvik argumenterer for at Sistani er en samlende figur som bidrar til å redde Irak som statskonstruksjon. Likevel er religiøst-basert lederskap en fragmenterende politisk kraft på sikt. Sistanis popularitet er omvendt proporsjonal med statens, skriver Selvik, og argumenterer med at en religiøs leder vanskelig kan bli politiker hvis målet er langvarig politisk stabilitet.
Nøkkelordet «stats- og medborgerskap» favner videre artikler som viser bredden i fruktbarheten av å bruke statsborgerskapstilnærmingen på tvers av tid og rom, og innen ulike disipliner som historie, økonomi og språkpolitikk. ROEL MEIJER skisserer opp historiske hendelser - konflikter og former for samarbeid mellom samfunnsgrupper og herskere i Egypt siden 1850-årene. Han antyder at statsborgerskapstilnærmingen kan sees som en ny disiplin i studiet av Midtøsten fordi historiske hendelser kan leses politisk på en annen måte enn de hittil er blitt ved å framheve måter statsborgerskap har blitt utøvd og uttrykt over tid.

FANNIE AGERSCHOU-MADSEN drøfter migrantarbeidernes uunnværlige sosiale og økonomiske rolle på arbeidsmarkedet i Saudi-Arabia. Til tross for forsøk på å «saudifisere» arbeidsstokken, argumenterer hun for at Saudi-Arabia, sammen med de fem andre oljerike gulfstatene der ikke-borgere utgjør en majoritet i befolkningen, er strukturelt avhengige av billig arbeidskraft, noe som vanskeliggjør politiske visjoner om nasjonalisering av arbeidsstokken. 
Arabisk språk utgjør en kulturell og identitetspolitisk påle for den store majoriteten innbyggere i Midtøsten. I hver sin artikkel tar GUNVOR MEJDELL og JАСОВ HØIGILT utgangpunkt i utviklingen av språkpolitikken i Egypt som ledd i revolusjonære endringer. De viser hvordan medborgerskap uttrykkes gjennom formelle og uformelle kanaler. Høigilt trekker fram den egyptiske dialektens demokratiserende funksjon under og etter revolusjonen i 2011 gjennom en eksplosiv vekst av satirisk litteratur og tegneserier for voksne. Begge sjangre uttrykker, ifølge ham, sosial og politisk kritikk i en folkelig språkdrakt med innslag av dialekt og humor. Mejdell tar utgangspunkt i den egyptiske nasjonalforsamlingen som behandler et forslag fremmet i november 2017 fra Språkakademiet i Kairo. Her foreslås fengselsstraff og bøter for journalister som skriver på talemål, det vil si egyptisk dialekt. Mejdell spør om Språkakademiets ekstreme forslag er uttrykk for kultureliters motstand mot endringer i språkformer. Hun ser på spenninger mellom det arabiske språkets politiske rolle som tale- og skriftspråk i den enkelte arabiske stat, og som fellesnevner for et panarabisk regionalt kulturelt fellesskap i lys av begrepet "superdiversity» - et begrep som dekker mangfold i morgendagens arabiske språkfellesskap.
Det tredje nøkkelordet «territorium» avspeiler konflikt, krig og forhandling om landområder som ikke er konsoliderte statskonstruksjoner selv om de utgjør stater i folkerettslig forstand: Israel/Palestina, Libya og Afghanistan. HILdE HENRIKSEN WAAGE Og JØRGEN JENSEHAUGEN tar opp måten Palestina som nasjonalstat for palestinere er blitt forhandlet bort siden 1947 ved at Israel har tatt kontroll over territoriet gjennom en kombinasjon av maktbruk og diplomati. Først forhandlet Israel opp sitt eget territorium mellom 1947 og 1949, for deretter å forhandle ned størrelsen på det gjenstående palestinske territoriet mellom 1993-1995 gjennom Oslo-forhandlingene. Forfatterne argumenterer for at Israel evnet å omgjøre konfliktløsning til territoriell ekspansjon. Dette skjedde dels ved at Israel vant maktspillet $\mathrm{i}$ møte med stormakter, og dels ved at israelere skapte og utnyttet territorielle tvetydigheter i avtaletekstene. I begge tilfeller presset israelske myndigheter gjennom fordelaktige forhandlingsresultater som sikret seg landet og sørget for at palestinerne ikke fikk noen stat.

DAG TUASTAD har gjort feltarbeid i Galilea i Nord-Israel, nærmere bestemt i landsbyen Deir Al Asad som Butenschøn introduserte ham for. Han drøfter betydningen av territorialitet blant palestinere i Nord-Israel, og søker å forstå hvorfor over halvparten av palestinerne som bodde i Galilea ble værende igjen i sine landsbyer, mens nær 90 prosent av palestinere ellers i landet -700000 av 800 ooo - ble flyktninger i løpet av 1948-krigen. Noe av forklaringen kan, ifølge ham, spores i småbrukeres lokalisme og rurale palestineres bånd til jorda. Dette gir seg uttrykk i klansolidaritet basert på tilhørighet til jorda, noe som utgjør en kjerne $\mathrm{i}$ israelske palestineres anti-koloniale kollektive bevissthet. 
Hva må til for å kalle et territorium for et land? I hver sin artikkel viser KNUT s. VIKøR Og THOMAS HEGGHAMMER hvordan to ulike landområder i en utvidet Midtøsten er blitt de-territorialisert i nyere tid: i Libya gjennom en deling av landet i en østlig del - Cyreneica - og en krigsherjet vestlig del Tripolitania - i kjølvannet av krigen i 2011, og i Afghanistan gjennom transnajonale jihadistiske bevegelser som har brukt afghansk territorium som tilholdssted siden 1980-årene. Vikør diskuterer hvorvidt og på hvilke måter Libya, slik landet har eksistert i over hundre år, kan kategoriseres som et land. Cyreneica og Tripolitania utgjorde nemlig to områder før Italia forente dem med kolonial makt i 1911. Det som samlet Libya står svakere etter Qadhafis fall i 2011, påpeker Vikør. Det pågår diskusjoner omkring skillet mellom landsdelene, og kamphandlinger omkring spørsmål knyttet til autonomi, føderalisme og oppdeling av Libya i to eller flere stater.

«Når kom egentlig jihadismen til Skandinavia?» Med dette spørsmålet retter Thomas Hegghammer vår oppmerksomhet til et brennaktuelt felt som Inga Brandell og Annika Rabo kommenterer innledningsvis, nemlig terrorismeog jihadismeforskning som et nordisk fenomen, et felt hvor skandinaviske forskere gjør det skarpt internasjonalt. Hegghammer viser at jihadisme, definert som transnasjonal voldelig islamisme, $\mathrm{i}$ Norden er eldre enn tidligere antatt. Han påpeker at det allerede i 1985 fantes militante miljøer i Danmark og Sverige med tilknytning til krigen i Afghanistan som oppsto i kjølvannet av Sovjetunionens invasjon av landet i 1979. Den afghanske motstandsbevegelsen mujahidin nøt sympati fra muslimske så vel som vestlige land. Sympatien hadde et skandinavisk avtrykk i kontakt mellom muslimer i Skandinavia og arabiske fremmedkrigere i Peshawar på midten av 1980-årene, noe Hegghammer viser gjennom nyoppdagede primærkilder som her presenteres for første gang.
Til dette spesialnummeret av Babylon har vi også den store gleden av å publisere en bildeserie med en rekke fotografier av ARE HOVDENAK. Disse ligger tematisk nært opp til Butenschøns akademiske virke, og spenner vidt i tid og rom - fra Algerie via Gaza-stripen til Iran, fra 1989 til 2002. Det de har til felles er folk uten land. Enten som et resultat av fordrivelse, forfølgelse eller okkupasjon. Mens kurderne er et splittet folk innenfor flere statsgrenser, er palestinerne og sahrawiene fordrevet og okkupert. Gjennom Hovdenaks blikk ser vi mennesket i tragedien.

Bildene avspeiler noe som karakteriserer Nils' akademiske virke aller mest, nemlig kombinasjonen av teoretisk tilnærming til statsborgerskap, krig og menneskerettigheter og et praktisk organisatorisk talent. I tillegg til å være redaksjonsmedlem i Nordic Journal of Human Rights, Journal of Citizenship Studies og Babylon, har Butenschøn hatt lederjobber blant annet i valgkomiteen for styret i Det norske Flyktningeråd (2002-2005) og Utvalg for samisk forskning og høyere utdanning (Butenschøn-utvalget, 20102012). Nils har også kommentert krig og konflikt i Midtøsten i media ved å trekke historiske tråder opp mot aktuelle politiske begivenheter. Han staket eksempelvis fram en rolle som nøktern kommentator av Israel-Palestina-konflikten og bygget under argumenter for palestineres rett til et hjemland ved hjelp av folkeretten. Meningsmotstandere oppfattet ham som en aktivistisk akademiker uten at det gikk ut over hans faglige integritet. 
Hvem skulle tro at ferden til forskning rundt Israel-Palestina-konflikten og solidaritetsarbeid i Palestinafronten (som leder og som redaktør av Palestina-nytt) startet med en bil fullastet med mat, pledd og annet nødutstyr for å hjelpe israelere i etterkant av Seksdagerskrigen i 1967? Skrur vi drøye femti år tilbake i tid, sitter 18 -årige Nils som russ bak rattet med nesa vendt mot Det hellige land sammen kamerater for å vise solidaritet med israelere i deres kamp mot palestinere. Inspirert av Odd Nansens dagbøker fra fengsel og hans arbeid med å redde jøder fra deportering til nazistenes dødsleirer under Den andre verdenskrig, så Nils en mulighet til selv å yte hjelp. En britisk militærambulanse ble innkjøpt til formålet. Men, det ble ikke noe av turen til Israel - den forble en drøm. Ungdomsvyene om Israel bar likevel frukter noen år senere i form av en bok, ironisk nok med tittelen Drømmen om Israel: Historiske og ideologiske forutsetninger for staten Israel (Universitetsforlaget, 1983 / nyutgitt i 2006). Gymnasiasten Nils hadde med tiden endret politisk posisjon fra et sterkt pro-israelsk syn, og fått ny forståelse av at forfølgelsen av jøder ikke rettferdiggjorde at palestinerne mistet retten til landet sitt. Innsyn i drivkrefter bak skjeve maktforhold i Palestina-Israel-konflikten, og politiske og historiske analyser om arabisk nasjonalisme og storpolitikk i Midtøsten utkom senere i boka Midtøsten. Imperiefall, statsutvikling, kriger (Universitetsforlaget, 2008).

Nils A. Butenschøns forskningsarbeid har alltid vært politisk fundert, samtidig som han har maktet å bevare forskerens faglige og resonnerende blikk. Som direktør ved daværende Institutt for menneskerettigheter uttalte han i 2002 i et intervju i Forskningsmagasinet Apollon: «Jeg har allid vært et politisk menneske, og forskningsarbeidet som gjøres her ved instituttet, har i bred forstand politisk relevans.» Han trakk fram arbeidet med en høringsuttalelse om et forslag til lovtiltak mot terrorisme. «Her er det særdeles viktig at instituttet er på banen. Vi må bidra til at sentrale rettsstatsprinsipper ikke blir overkjørt av statsmaktens behov for kontroll over innbyggerne», sa han. Uttalelsen vitner om en statsborgerskapstilnærming som lå direktørhjertet nært både faglig og politisk på måter som fortsatt har relevans i dag.

Jubilanten hviler ikke på sine laurbær med det første. I samarbeid med Lars Mjøset og Kristian Berg Harpviken fordyper han seg i Stein Rokkans komparative metode i studiet av endringer i statssystemet i Midtøsten. Et spesialnummer viet Midtøsten av tidsskriftet Comparative Social Research som utgis ved $\mathrm{UiO}$ er under planlegging.

Denne utgaven av Babylon er redigert i samarbeid med Rania Maktabi som også har vært pådriver for dette prosjektet. Sammen med Butenschøn redigerte hun nylig boken Brennpunkt Midtøsten: Byene som prisme (Universitetsforlaget, 2018). Vi vil takke alle fagfeller, støttespillere, venner og kolleger som har bidratt både faglig og finansielt til å gjøre denne spesialutgaven av Babylon mulig. En spesiell takk til Fritt Ord, Institutt for kulturstudier og orientalske språk (IKOs) ved UiO og en hel rekke gratulanter for økonomisk støtte til å realisere prosjektet.

Som alltid er Babylon åpent tilgjengelig via Universitetet i Oslos FRITT-portal:

journals.uio.no/index.php/babylon/index.

\section{Redaktørene,}

RANia MAKTABI, Høgskolen i Østfold.

ERIK SKARE, Universitetet i Oslo.

ERLING LORENTZEN SOGGE, Universitetet i Oslo. 